\title{
Color Trails Test: a Brazilian normative sample
}

\author{
Ivan Sant' Ana Rabelo ${ }^{1,2}$, Sílvia Verônica Pacanaro ${ }^{2}$, Milena de Oliveira Rossetti ${ }^{1,2}$, Irene F. \\ Almeida de Sá Leme ${ }^{2}$, Nelimar Ribeiro de Castro $^{3}$, Camila Marchi Güntert ${ }^{2}$, Eliane Correa \\ Miotto $^{1}$ and Mara Cristina Souza de Lucia ${ }^{1}$ \\ 1 Universidade de São Paulo, Brazil \\ 2 Casa do Psicólogo, Brazil
}

3 Universidade São Francisco, Brazil

\begin{abstract}
The present study aims to evaluate psychometric data on the population of Brazil using of the Color Trails Test (CTT). The instrument was applied to 1,942 subjects who came from the north $(1.4 \%)$, northeast $(10.4 \%)$, midwest $(7.7 \%)$, southeast $(65.9 \%)$, and south $(13.9 \%)$ regions of Brazil. Ages varied from 18 to 86 years $(\mathrm{M}=40.03$ years; $\mathrm{DP}=16.02)$, with 386 males $(19.9 \%)$ and 1,556 females $(80.1 \%)$. Regarding schooling, $57(3 \%)$ of participants were illiterate, $1.240(64 \%)$ had primary education and $645(33 \%)$ had a high school and/or superior diploma. The length of schooling ranged from 0 to $14(\mathrm{M}=7.81, \mathrm{SD}=3.51)$ years. Good accuracy ratings were obtained using Spearman's coefficient on the main measures of the CTT, including time of execution form 1 (0.76) and form 2 (0.82). Regional variations showed that the northeast region had the worst results on the instrument. Males had better performance on the proposed task, with significant differences between age groups and the worst results for ages greater than 60 years. For both sexes, an increase in score was noticed with increasing age, and better performance was found with increasing levels of education. The present results suggest that the CTT can identify attentional disturbances with significant variations in the time of execution. Keywords: neuropsychological test, attention, executive functions.
\end{abstract}

Received 1 April 2010; received in revised form 10 May; accepted 20 May 2010. Available on line 26 June 2010

\section{Introduction}

Attention is a complex mental function involving the skill of a person to focus on a stimulus from an environmental or internal context. This selection skill is fundamental to maintaining mental activity. Through

Ivan Sant' Ana Rabelo, Universidade de São Paulo, Brazil; Department of Research and Test Production, Casa do Psicólogo Bookstore and Publisher, São Paulo, Brazil. Sílvia Verônica Pacanaro, Department of Research and Test Production, Casa do Psicólogo Bookstore and Publisher, São Paulo, Brazil. Milena de Oliveira Rossetti, Universidade de São Paulo, Brazil; Department of Research and Test Production, Casa do Psicólogo Bookstore and Publisher, São Paulo, Brazil. Irene F. Almeida de Sá Leme, Department of Research and Test Production, Casa do Psicólogo Bookstore and Publisher, São Paulo, Brazil. Nelimar Ribeiro de Castro, Laboratory of Educational Psychology, Universidade São Francisco, Itatiba, Brazil. Camila Marchi Güntert, Department of Research and Test Production, Casa do Psicólogo Bookstore and Publisher, São Paulo, Brazil. Eliane Correa Miotto, Department of Neurology and Psychology Division and Mara Cristina Souza de Lucia, Psychology Division, Central Institute, Hospital das Clínicas, School of Medicine, Universidade de São Paulo, Brazil. Correspondence regarding this article should be directed to: Ivan Sant' Ana Rabelo, Rua Simão Álvares, 1020, Vila Madalena, São Paulo, SP, Brazil, 05417-020. E-mail: ivan@ casadopsicologo.com.br attention, the stimulus that derives from the environment and which a person receives continuously can be controlled (Barton, Strauss, \& Reilley, 1995; Lent, 2001; Lezak, 1995; Matlin, Machado, \& de Lima, 2004). Sternberg, Costa and Haase (2008) posited that humans utilize these attentional resources together with other cognitive functions, such as memory and motor skills, to filter appropriate responses from the environmental stimuli.

Attention is a function with many subtypes, Eysenck and Keane (2007), Matlin (2004) and Sternberg (2008) note four functions of attention: selective attention, vigilance, search and divided attention. Selective attention leads the individual to respond selectively to certain stimuli and inhibit those that are irrelevant. With regard to sustained attention, Chan (2001) emphasized that a person must maintain focus on a particular aspect for a sustained period of time while filtering elements that distract from the task that is being performed. Divided attention, in contrast, refers to individuals maintaining attention on different stimuli to execute two or more distinct tasks simultaneously. Performance on a divided attention task depends on many factors, such as similarity, practice, and difficulty (Dalgalarrondo, 2000; Eysenck, Keane, \& França, 2007). Regarding the search, this is the ability to select relevant stimulus and direct attention to it. 
Research conducted by Moll, Oliveira-Souza, Moll, Bramati and Andreiuolo (2002) used functional magnetic resonance imaging (fMRI) to investigate cerebral functioning and its relationship with the Trail Making Test (TMT). Seven right-handed normal volunteers with ages ranging from 19 to 43 years (mean $=24 \pm 9$ years) participated in the study. During the implementation of the instrument (TMT), images were being logged via resonance and the results showed that TMTB were lengthier than their A counterparts. Also, TMTB demanded more attentional effort than TMTA, but the data does not show statistical relevance $[F(1.5)$ $=53.2, p<.002]$. Areas of increased activation during performance of TMTB as compared to TMTA, showed that the left hemisphere was more activated than the right, with an overall lateralization index of -.63. Activations peaked in the lower third of the dorsolateral prefrontal cortex, premotor cortex, left medial frontal cortex and bilaterally in the intraparietal sulcus (IPS). The frontal lateralization index was -1.00 , with all activations falling in the left hemisphere. The parietal lateralization index was .37. These findings are in line with clinical, anatomic and functional neuroimaging data that point to a critical role of the dorsolateral and medial prefrontal cortices as well as the intraparietal sulci in the regulation of cognitive flexibility, intention, and the covert execution of saccades/anti-saccades.

Instruments that evaluate attention are cited in the literature, such as the study of Frankston, Lebowitz, Kapust, Bules and O'Connor (2007), which examines the difference between the Trail Making Test (TMT) and the Color Trails Test (CTT) and signaled that the TMT proved to be an appropriate measure to evaluate the performance of individuals that have a cognitive deficit, but that it is only useful for individuals who know the American alphabet, making it impossible to be applied to people who don't know the English language or are illiterate. The CTT proved to be an alternative attention evaluation in several countries, because it uses numbered colored circles and universal language symbols and does not depend on knowledge of the English alphabet.

D’Elia, Satz, Uchiyama and White (1996) applied the international version of the CTT to a group of 1,528 participants without a history of neurological, psychiatric, or psychosocial problems that could interfere in neuropsychological test performance. Three ethnic subgroups were formed (Caucasian, Hispanic, and Afro-American), with an average age of (57.72 years; $\mathrm{DP}=20.06)$. The average formal education level of the sample was 14.13 years $(\mathrm{DP}=3.52)$, with higher levels of education in males than females, once they constituted just $12 \%$ of the sample. The results showed decreased performance with increasing age. The participants who had higher education levels and were aged between 18 and 29 years had better performance on CTT form 1 $(\mathrm{CTT} 1 ; \mathrm{M}=26 \mathrm{~s} ; \mathrm{DP}=8.47)$ and CTT $2(\mathrm{M}=56 \mathrm{~s}$; DP
$=16.23)$. Those with minimal education levels and aged above 75 years had higher scores on the CTT, with worse performance on CTT $1(\mathrm{M}=73 \mathrm{~s}$; DP = 24.74) and CTT 2 $(\mathrm{M}=144 \mathrm{~s} ; \mathrm{DP}=45.51)$. For the gender and age variables, neither significantly related to raw scores on the CTT after removing the effects of age, which accounted for $0.4 \%$ to $2.4 \%$ of the variance. The instrument test-retest precision $(N=27)$ was found to be good using Pearson's correlation coefficient for the time of test execution variable (CTT 1, $r=.64$; CTT 2, $r=.79)$.

The Color Trails Test (CTT; D’Elia, Satz, Uchiyama, $\&$ White, 1996) measures remote divided attention and sustained attention, abilities that are considered to reflect frontal lobe perceptual tracking function (i.e., ability to locate different elements within a predetermined time), sequenciation (i.e., ability to achieve numeric order according to the required task), and motographic ability (i.e., ability to achieve fine motor coordination suitable to the task). The CTT has been used as a neuropsychological test in clinical practice, hospitals, and academia, with regard to the importance of instruments that assess sustained attention and divided attention.

Research using CTT with other variables has been found in the literature. Lee and Cheung (2005) analyzed the relationship between visual perception and attention in 94 subjects, with 47 subjects diagnosed with schizophrenia and 47 subjects used as a control. All participants were subjected to a battery of neuropsychological tests that evaluated intelligence, auditory and divided attention, attentional control processes, perceptual-visual organization ability, and visual spatial perception ability. The CTT was used to measure divided attention, and the results indicated a relationship between perceptual-visual function and attention only among schizophrenia patients, who showed the most difficulty in this aspect of the test compared with the control group.

Regarding the evaluation of individuals with acquired brain damage who sought to obtain a driver's license, Hartman-Maeir, Erez, Ratzon, Mattatia and Weiss (2008) tested 30 subjects using the CTT 1 and CTT 2. The subjects also underwent traffic evaluation with a driving rehabilitation specialist and an instructor. The approved participants on the traffic test completed the CTT 1 and CTT 2 more quickly than those who failed the test, although the difference between groups was significant only for the CTT 1 . These results indicate the necessity of conducting new studies with representative samples to obtain data for this population which may contribute to decreased traffic accident risks.

The relationship between substance use and impulsive personality traces was studied by Dolan, Bechara and Nathan (2008) in 38 patients with a history of substance abuse compared with a control group comprising 30 participants. The study used the Wisconsin Card Sorting Test, CTT, Stroop test, Wechsler Adult 
Intelligence Scale -WAIS-II (Digit Span), and Iowa Gambling Task. Individuals with a history of substance abuse and impulsive personality traces exhibited lower performance on the tasks involving executive function, attention, and memory compared with control subjects.

Presently in Brazil, different instruments are commonly used to assess attention processing, mostly with favorable consideration from the Federal Council of Psychology (CFP) for commercialization of concentrated attention tests in Brazil (Boccalandro, 1977; Brickenkamp, 2000; Cambraia, 2002; Tonglet, 1999), but there is only one instrument to test divided and sustained attention, specifically for attaining a Brazilian driver's license. Sisto, Noronha, Lamounier, Bartholomeu and Rueda (2006) sought to find evidence to validate instruments that assess divided attention (AD) and sustained attention (AS) in 369 subjects ranging in age from 18 to 73 years $(\mathrm{M}=27.70$ years; $\mathrm{DP}=11.50)$, with 265 (61.8\%) males and 167 (38.2\%) females. With regard to the quality and concentration speed measures on the divided attention test, performance was found to be a function of age, with younger subjects exhibiting better performance on the task. The authors concluded that a specific standard needed to be developed to effectively interpret this instrument based on age. With regard to sustained attention, similar results to divided attention were found on the quality and concentration speed measures. Similar results between ages were found on the maintenance measure, indicating that this measure does not change with age.

Nitrino et al. (2005) investigated behavioral patterns using instruments, questionnaires, and scales to test clinical diagnostic attention in Alzheimer's disease patients in Brazil. The authors performed a bibliographical survey of attention research literature in the PubMed and LILACS databases that investigated functional changes that occur during the disease. One of the most widely reported instruments was the CTT. The literature review revealed patterns in the CTT in a Brazilian population that may aid in the evaluation of attention and most bounded functions to achieve effective interventions in the disease.

The above research indicates that tests that evaluate attention play an important role in diagnosis and intervention. Attention tests that are able to characterize and detect severity may aid in the development of proper therapies. Psychological test instruments must be evaluated in several populations from various regions so that researchers may determine their psychometric properties.

\section{Methods}

\section{Participants}

The sample was composed of 1,942 subjects who came from the north (1.4\%), northeast $(10.4 \%)$, midwest (7.7\%), southeast (65.9\%), and south (13.9\%) regions of Brazil, indicating good geopolitical distribution. Ages ranged from 18 to 86 years $(\mathrm{M}=$ 40.03; DP $=16.02)$, with 386 males $(19.90 \%)$ and 1,556 females $(80.10 \%)$. Regarding schooling, 57 $(3 \%)$ of participants were illiterate, $1.240(64 \%)$ had primary education and $645(33 \%)$ had a high school and/or superior diploma. The length of schooling ranged from 0 to $14(\mathrm{M}=7.81, \mathrm{SD}=3.51)$ years.

Individuals with a history of substance abuse, neurological problems or any other problem that could interfere with the performance in the test were excluded from the sample.

\section{Color Trails Test}

The CTT was originally created by D'Elia, Satz, Uchiyama and White (1996). Currently in Brazil, the instrument is the standard process used by the Casa do Psicólogo Library and Editors Research Department. The CTT is administered to individuals over 18 years of age and consists of using a pencil to connect, in ascending order, 25 numbers (CTT 1) and alternate colors (CTT 2) in "the shortest time possible". For the CTT 1, the examinee is instructed to quickly trace a line that unites circles numbered from 1 to 25 in the correct order. The fact that the color changes in each consecutive circle is not mentioned to the participant. The examinee must complete the training before beginning the test, the results of which are evaluated. In cases of errors, the examiner indicates the error and instructs the examinee to correct the error and continue with the task. The examinee has 10 seconds to link a circle to another circle, after which time the examiner must nonverbally indicate (e.g., pointing with a finger) the next correct circle position. The time needed for the examinee to accomplish the task is recorded in seconds. Error and near-error frequencies are recorded, in addition to the number of interventions made by the examiner (i.e., warnings). A near-error response occurs when the examinee incorrectly starts the path toward a circle, but then corrects it spontaneously before reaching the incorrect circle. No intervention is required in this type of response.

For the CTT 2, the examinee is instructed to quickly trace a line between numbered circles, obeying the number sequence but alternating between pink and yellow (i.e., the examinee must trace the line from pink circle 1 to yellow circle 2, not to pink circle 2, and then to pink circle 3 , not to yellow circle 3 ), and so on. The examinee completes the training before proceeding with the test. The names of the colors (e.g., "pink" and "yellow") must not be mentioned during the training instruction. The examiner must point and say "of that color." The time needed for the examinee to complete the stage is recorded in seconds. Color error and nearerror frequencies are recorded, in addition to the number of interventions by the examiner (i.e., warnings). 


\section{Evaluated functions}

The CTT 1 tests perception tracking and sustained attention and allows the observation of motographic ability. The CTT 2 evaluates the same functions and also divided attention and sequenciation because it demands sequential alternations of colors and numbers. The CTT 1 requires the examinee to follow a numeric sequence, and the CTT 2 requires the examinee to divide attention and simultaneously follow the alternating sequence of colors and numbers.

However, simple perceptual tracking and sustained attention are necessary for achieving good performance on both forms, and separating performance on CTT 2 into the relative impact of those abilities and divided attention, alternation, and sequenciation is difficult. The errors, warnings, and near-errors on the CTT for now are considered experimental and are mostly presented only for research purposes. These data are considered to reveal qualitative aspects of cognitive commitment or cognitive slippage.

The interference measure rightly contributes to this differentiation. This measure represents the difference between performance on the CTT 1 and CTT 2 and is expressed as a function of performance level on the CTT 1. Consequently, it is a "pure" measure of interference (or interference resistance) attributed to the demands of alternation and sequenciation on the CTT 2. A score of 1.0 on the interference measure indicates that to complete the CTT 2 the examinee took twice the time necessary to complete CTT 1 . A score of 4.0 indicates that the time needed to complete the CTT 2 was fivefold greater than the time spent to complete the CTT 1.

\section{Procedure}

After approval of the research project by the Ethics Committee, psychologists from the Center of Studies in Health Psychology, University of São Paulo (CEPSIC) Brazil Neuropsychology Specialization Program from several regions of Brazil were trained in 2007 to apply the CTT to a standard sample of subjects. The training was offered to the Casa do Psicólogo Library and Editors Research Department research team. The instrument was applied individually according to the participants' availability. The application occurred voluntarily after communicating to the participants the importance of the research and receiving written informed consent.

\section{Results}

Data were analyzed using the Statistical Package for the Social Sciences (SPSS) software. Test-retest precision data were analyzed using Spearman's correlation coefficient. Regional variations in performance were determined using analysis of variance (ANOVA), with values of $p<.05$ considered statistically significant. The impact of age on performance in several CTT measures was assessed using Student's $t$-test with independent samples. Further impacts of age and education level on CTT performance were determined using Pearson's correlation.

\section{Precision}

CTT precision was investigated using Spearman's correlation coefficient. The sample for this study was composed of 90 participants, with ages ranging between 19 and 79 years $(M=43.87$; $\mathrm{DP}=16.32)$, with 56 females $(62.20 \%)$ and 34 males $(37.40 \%)$. The results indicated good indices of precision on the main measures of the CTT, including time of execution (CTT 1: $r=0.76, p=.000$; CTT 2: $r=$ $0.82, p=.000)$ and the number of warnings (CTT $1: r=0.62, p=.000$; CTT 2: $r=0.79, p=.000)$, with good temporal stability. For the other indices, we opted to use Student's $t$-test to analyze the data between the first and second administration because they present less amplitude and distribution, which makes the use of correlation coefficients impossible. This analysis indicated nonsignificant differences in error numbers (CTT 1: $t[178]=.30, p=.762$; CTT $2: t[178]=.00, p=1.000)$ and near-errors $(\mathrm{CTT}$ $1: t[178]=.00, p=1.000 ;$ CTT $2: t[178]=.23, p$ $=.815)$ and on the interference measure $(t[178]=$ -.54, $p=.590)$. However, a significant difference was found for the number of color errors on the CTT $2(t[178]=2.36, p=.019)$.

\section{Analysis of variance}

Based on the "participants" item, we determined if any significant differences existed in average CTT scores considering the region. Significant differences were found in time of execution (CTT 1: $F(1924 ; 4)=$ $11.94, p=.000$; CTT 2: $F(1924 ; 4)=14.19, p=.000)$ and number of warnings (CTT 1: $F(1924 ; 4)=3.84, p=$ .004 ; CTT 2: $F(1924 ; 4)=4.66, p=.001)$.

\section{Evidence of validation related to the development}

Possible differences were investigated between genders using Student's $t$-test on several measures of the CTT. No significant differences were observed in the number of errors on the CCT 1, the number of numeric errors on the CTT 2, or the interference measure. Significant differences were found between males and females on the other measures (i.e., time of execution, number of errors, nearerrors, errors in colors, and warnings), with females presenting higher averages, indicating that longer times to complete the instrument reflected worse performance. Males performed better than females on the proposed attention task.

We then used ANOVA to determine whether significant differences existed between age groups (i.e., 18 to 29 years, 30 to 59 years, and $>60$ years) (Table 1 ). 
Table 1. Analysis of age groups (ANOVA) in the Color Trails Test.

\begin{tabular}{|c|c|c|c|}
\hline & $\boldsymbol{F}$ & gl & $p$ \\
\hline \multicolumn{4}{|l|}{ CTT form 1} \\
\hline Time of execution & 201.57 & 2 & .000 \\
\hline Number of errors & 9.60 & 2 & .000 \\
\hline Number of near-errors & 6.95 & 2 & .001 \\
\hline Number of warnings & 48.39 & 2 & .000 \\
\hline \multicolumn{4}{|l|}{ CTT form 2} \\
\hline Time of execution & 214.81 & 2 & .000 \\
\hline Number of errors in colors & 10.60 & 2 & .000 \\
\hline Number of numeric errors & 12.09 & 2 & .000 \\
\hline Number of near-errors & 7.63 & 2 & .000 \\
\hline Number of warnings & 75.30 & 2 & .000 \\
\hline Interference Measure & 6.59 & 2 & .001 \\
\hline
\end{tabular}

Table 2. Analysis of time of execution (form 1 and 2) and interference measure (Tukey test).

\begin{tabular}{|c|c|c|c|c|}
\hline \multicolumn{5}{|c|}{ Time of Execution - form 1} \\
\hline \multirow{2}{*}{ Age Group } & \multirow{2}{*}{$N$} & \multicolumn{3}{|c|}{ Subgroups to $\alpha=.05$} \\
\hline & & 1 & 2 & 3 \\
\hline 18 to 29 & 639 & 46.62 & & \\
\hline 30 to 59 & 1008 & \multicolumn{3}{|c|}{58.39} \\
\hline 60 or above & 295 & & & 100.67 \\
\hline$p$ & & 1.000 & 1.000 & 1.000 \\
\hline \multicolumn{5}{|c|}{ Time of Execution - form 2} \\
\hline \multirow{2}{*}{ Age Group } & \multirow{2}{*}{$N$} & \multicolumn{3}{|c|}{ Subgroups to $\alpha=0.05$} \\
\hline & & 1 & 2 & 3 \\
\hline 18 to 29 & 639 & 87.09 & & \\
\hline 30 to 59 & 1008 & \multicolumn{3}{|c|}{115.16} \\
\hline 60 or above & 295 & & & 178.39 \\
\hline$p$ & & 1.000 & 1.000 & 1.000 \\
\hline \multicolumn{5}{|c|}{ Interference Measure } \\
\hline Age Group & $N$ & & & \\
\hline 18 to 29 & 639 & .972 & & \\
\hline 60 or above & 295 & .997 & .997 & \\
\hline 30 to 59 & 1008 & & 1.100 & \\
\hline$p$ & & .848 & .068 & \\
\hline
\end{tabular}

Significant differences were found on all performance variables. We then used the Tukey test to determine differences among groups with regard to time of execution on the CTT 1 and CTT 2 and the interference measure. (Table 2)

The three groups significantly differed in time of execution on the CTT 1 and CTT 2, with greater ages having higher scores and the worst performance with ages $>60$ years. Younger subjects had lower averages than the older subjects, establishing a direct relationship between score and age. These results indicate that age exerted an important influence on CTT performance with lower scores and better performance in younger people.

Another variable investigated was education level. Fifty-seven subjects (2.9\%) were uneducated, 1,240 $(63.9 \%)$ completed grade school, and 645 (32.66\%) completed high school or had higher education. Education level ranged from 0 to 14 years $(\mathrm{M}=7.81$ years; DP = 3.51). The impact of education on time of execution on the CTT 1 and CTT 2 was analyzed using the Tukey test. (Table 3)

The three groups significantly differed, with the uneducated group having the highest averages, followed by the grade school group and the high school and higher education group. These results indicate that higher levels of education had better CTT performance. Despite significant differences between groups in the ANOVA of the interference measure, no difference was found between groups using the Tukey test. 
Table 3. Effect of education level on time of execution (forms 1 and 2) (Tukey test)

\begin{tabular}{|c|c|c|c|c|}
\hline \multicolumn{5}{|c|}{ Time of Execution - form 1} \\
\hline \multirow{2}{*}{ Education Level } & \multirow{2}{*}{$n$} & \multicolumn{3}{|c|}{ Subgroups to $\alpha=.05$} \\
\hline & & 1 & 2 & 3 \\
\hline High school and higher education & 645 & 46.899 & & \\
\hline Grade school & 1240 & & 64.187 & \\
\hline Uneducated & 57 & & & 149.228 \\
\hline$p$ & & 1.000 & 1.000 & 1.000 \\
\hline
\end{tabular}

Time of Execution - form 2

\begin{tabular}{|c|c|c|c|c|}
\hline \multirow{2}{*}{ Education Level } & \multirow{2}{*}{$n$} & \multicolumn{3}{|c|}{ Subgroups to $\alpha=.05$} \\
\hline & & 1 & 2 & 3 \\
\hline High school and higher education & 645 & 87.38 & & \\
\hline Grade school & 1.240 & & 123.93 & \\
\hline Uneducated & 57 & & & 251.28 \\
\hline$p$ & & 1.000 & 1.000 & 1.000 \\
\hline
\end{tabular}

\section{Discussion}

The objective of this work was to standardize the Brazilian version of the CTT, which evaluates sustained and divided attention by assessing perceptual tracking, sequenciation, and motographic abilities. The precision indices and validation related to gender, age, and education level were also investigated. The precision indices showed temporal stability through the variable of time of execution and the interference measure. The indices found for the time of execution variable in the Brazilian sample were superior to those observed with the original instrument.

The analysis of regional differences in performance on the CTT revealed that the northeast had systematically worse performance, and the north and south regions had better performance. These data, however, must be analyzed with caution because of the unequal distribution of participants in each region. The technical manual of this instrument suggests that the Brazilian sample is not normalized regarding this variable, emphasizing the need to increase the sample size.

The average male and female time of execution data on the CTT 1 and CTT 2 were significantly different. Women presented higher average scores, which corresponded to worse performance. These results contrast with data obtained in an American study, in which no significant differences in raw CTT scores were found between males and females after removing the effect of age (D'Elia et al., 1996). Sisto et al. (2007) observed better performance in males than females in attention evaluation, specifically concentrated attention. Despite the significant differences that were found between sexes in near-errors (CTT 1 and CTT 2) and numeric errors (CTT 2), these gender data were not normalized to this variable because they derive from experimental items that only contribute to qualitative interpretations and do not necessarily evaluate any specific function.

The average time of execution on the CTT 1 and CTT 2 was analyzed with regard to age to determine whether there were significant differences between groups. The data indicated that age exerted an important influence on CTT performance. Younger participants had the best performance on all variables of the CTT 1 and CTT 2. We observed differences between groups in the time of execution of both forms of the CTT, but the interference measure for individuals older than 60 years was not different. Therefore, the age data were not normalized to this variable. The present results are consistent with D'Elia et al. (1996) and Sisto et al. (2006), which showed that younger subjects had better performance on the CTT 1 and CTT 2, whereas older subjects (> 75 years) had worse performance on the instrument.

Significant differences were also observed in CTT performance between the three education level groups (uneducated, grade school, high school and higher education). The uneducated group had the worst performance. These results indicate that as education level rises, better performance can be expected on the CTT, which is consistent with D'Elia et al. (1996).

The CTT can be used to assess sustained and divided attention in several contexts to conduct a neuropsychological assessment, including clinics, hospitals, and schools, in order to assist in the diagnostic of Deficit Hyperactivity Disorder, Learning Disorders, 
and some types of Dementia. The CTT enables the identification of attentional disturbances whereof results that go a lot far of those observed to age groups and schooling level of Brazilian norms presented, and as scores over the level indicates disadvantage in the area which the variable refers to (D'Elia et al., 1996). This instrument was found to be very useful in several international studies that obtained good correlational indices (Dolan et al., 2008; Lee \& Cheung, 2005).

Among the advantages of the CTT, the numbers and colors are nearly universal symbols that demand little production or language knowledge. Additionally, the sequential alternation between numbers and colors on the CTT 2 requires greater frontal lobe function than perceptual tracking, sequenciation, and motographic abilities. Future studies should research the instrument further to determine its sensitivity and specificity for different clinical groups and to normalize the data for different populations. We emphasize the importance of developing instruments that allow epidemiological studies which subsidize aspects related to attention, particularly regarding the establishment of mental health public policy, considering the impact of these difficulties in the population's quality of life.

\section{References}

Barton, D.A., Strauss, B., \& Reilley, R.R. (1995). Doctoral dissertations on hypnosis: 1980-1989. American Journal of Hypnosis, 37, 267-270.

Brickenkamp, R. (2000). D2: Atenção Concentrada. São Paulo: Editora CETEPP.

Boccalandro, E.R. (1977). Teste de Atenção Concentrada - AC 15. São Paulo: Vetor Editora Psico-Pedagógica.

Cambraia, S.V. (2002). Teste de Atenção Concentrada - AC. São Paulo: Vetor Editora Psico-Pedagógica.
Chan, R.C.K. (2001). A further study on the sustained attention response to task (SART): the effect of age, gender and education. Brain Injury, 15, 819-829.

Dalgalarrondo, P. (2000). Psicopatologia e Semiologia dos Transtornos Mentais. Porto Alegre: Artes Médicas.

Dolan, S.L., Bechara, A., \& Nathan, P.E. (2008). Executive dysfunction as a risk marker for substance abuse: the role of impulsive personality traits. Behavioral Sciences and the Law, 26, 799-822.

D’Elia, L.F., Satz, P., Uchiyama, C.L., \& White, T. (1996). Color Trails Test: Professional Manual. Odessa, FL: Psychological Assessment Resources.

Eysenck, M.W., Keane, M.T., \& França, L.M. (2007). Manual de Psicologia Cognitiva. Porto Alegre: Artes Médicas.

Frankston, S.E., Lebowitz, B.K., Kapust, L.R., Hollis, A.M., \& O'Connor, M.G. (2007).

The use of the Color Trails Test in the assessment of driver competence: Preliminary report of a culture-fair instrument. Archive Clinical Neuropsychology, 22(5), 631-635.

Hartman-Maeir, A., Erez, A.B., Ratzon, N., Mattatia, T., \& Weiss, P. (2008). The validity of the Color Trail Test in the pre-driver assessment of individuals with acquired brain injury. Brain Injury, 22, 994-1008.

Lee, T.M.C., \& Cheung, P.P.Y. (2005). The relationship between visual-perception and attention in Chinese with schizophrenia. Schizophrenia Research, 72, 185-193.

Lent, R. (2001). Cem Bilhões de Neurônios: Conceitos Fundamentais de Neurociência. São Paulo: Editora Atheneu.

Lezak, M.D. (1995). Neuropsychological assessment. New York: Oxford University Press.

Matlin, M.W., Machado, S., \& de Lima, C.H. (2004). Psicologia Cognitiva. Rio de Janeiro: LTC Editora.

Moll, J., Oliveira-Souza, R., Moll, F.T., Bramati, I.E., \& Andreiuolo, P.A. (2002). The cerebral correlates of set-shifting an FmRI study of the trail making test. Arquivo de Neuropsiquiatria, 60(4), 900-905.

Nitrino, R., Caramelli, P., Bottino, C.M.C., Damasceno, B.P., Brucki, S.M.D., \& Anghinah, R. (2005). Diagnóstico de doença de Alzheimer no Brasil: avaliação cognitiva e funcional. Arquivo Neuropsiquiatria, 63, 720-727.

Sternberg, R.J., Costa, R.C., \& Haase, V.G. (2008). Psicologia Cognitiva. Porto Alegre: Artes Médicas.

Sisto, F.F., Noronha, A.P.P., Lamounier, R., Bartholomeu, D., \& Rueda, F.J.M. (2006). Testes de Atenção Dividida e Sustentada. São Paulo: Vetor Editora Psico-Pedagógica.

Tonglet, E.C. (1999). Bateria de Funções Mentais - BFM. São Paulo: Vetor Editora Psico-Pedagógica. 